\title{
An alternative mode to activate alcohols: application to the synthesis of $\mathbf{N}$-heteroarene derivatives
}

\author{
Xiaoping Liu, ${ }^{a}$ Jean-Marc Sotiropoulos ${ }^{b}$ and Marc Taillefer*a \\ The activation of readily available but poorly reactive alcohols can be carried out solely in the presence of the tert-butoxide \\ $\left(\mathrm{KO}^{\mathrm{t}} \mathrm{Bu}\right)$ / dimethylformamide (DMF) couple. This system allows the direct use of primary alcohols as alkylating agents to \\ functionalize the $\mathrm{C}\left(\mathrm{sp}^{3}\right)-\mathrm{H}$ bond of methyl azaarenes, in the absence of traditionally used transition metal-based catalysts. \\ Various alkylated $N$-heteroarenes such as pyridine, quinoline, pyrazine or quinoxaline derivatives have been obtained by this \\ method, which is supposed to proceed via the initial formation of an alkyl formate intermediate, as shown by experimental \\ and theoretical mechanistic studies.
}

\section{Introduction}

Alcohols are easy to handle and are widely available substrates. Moreover, their direct use to access bulk and fine chemicals is meeting increasing interest in line with the criteria of sustainable development. Indeed, as alcohols can be obtained from biomass and in particular from lignocellulose, they constitute an alternative and sustainable carbon source compared to fossil resources. ${ }^{1}$ However, alcohols are quite unreactive because the hydroxide is difficult to substitute, especially by nucleophiles. ${ }^{2 a}$ Common ways to transform it into a better leaving group are protonation or pre-functionalization into sulfonates or halides. However, this can incur several drawbacks, such as the deactivation of the nucleophile partner or the generation of additional waste. ${ }^{2}$

Herein, we present a new approach to make alcohols more reactive without pre-functionalization and in the absence of transition metal-based catalysts. This alternative activation way has been applied to the direct use of primary alcohols as alkylating agents to functionalise the $\mathrm{C}\left(\mathrm{sp}^{3}\right)-\mathrm{H}$ bond of methyl azaarenes. The method has thus provided valuable access to various types of $\mathrm{N}$-heteroarenes (such as pyridine, quinoline, pyrazine or quinoxaline derivatives), which are prevalent motifs in pharmaceuticals and agrochemicals, as building blocks for the synthesis of natural products and even in materials. ${ }^{3} \mathrm{The} \mathrm{C}\left(\mathrm{sp}^{3}\right)-$ $\mathrm{H}$ alkylation of methyl azaarenes has so far been performed either via the protonation of secondary alcohols (with a limited scope) or in the presence of very strong bases (BuLi, LDA, KDA, LiHMDS) associated to prefunctionalized electrophiles such as esters (with palladium catalysts) or halogenated alkyls. ${ }^{[4]}$ The use of the latter, often prepared from the corresponding alcohols, can lead to toxicity problems as many alkyl halides are mutagenic, ${ }^{2 a, 4}$ and generates halides salts as by-products. A recently-described more environmentally friendly alternative involves the direct use of typically less toxic alcohols as alkylating reagents. Based on an increased alcohol reactivity and known as a borrowing-hydrogen process, it was successfully applied for the $\mathrm{C}\left(\mathrm{sp}^{3}\right)-\mathrm{H}$ alkylation of methyl azaarenes. The activation step corresponds to a hydrogen abstraction of an alcohol and its oxidation to a more reactive aldehyde, catalysed by a transition metal complex. Under basic conditions, an aldehyde and methyl azaarene leads to the formation of an alkene and, via hydrogenation by an in situ formed transient metal hydride species, to the C-alkylation product. ${ }^{2}$ After an initial breakthrough in this field, reported by Kempe et al. which described the alkylation of methyl azaarene with primary alcohols in the presence of a well-defined iridium-complex catalyst, ${ }^{5}$ the principle was applied in the presence of various transition metal-based catalysts (Scheme $1 \mathrm{~A}$ ).

$$
\begin{aligned}
& \text { Activation of alcohols via transition metal catalyzed borrowing-hydrogen (A) } \\
& \text { Solvent }=\text { toluene, } x y l e n e, \text { diglyme, 1,4-dioxane, } T H F \\
& \overbrace{n=1}^{Y} \\
& +\mathrm{HO}_{\mathrm{R}} \underset{\mathrm{KO}^{t} \mathrm{Bu} / \text { solvent }}{\left[\mathrm{M}^{\top}\right] \text { cat }} \\
& \mathrm{M}^{\top}=\mathrm{Ni}, \mathrm{Co}, \mathrm{Ir}, \mathrm{Ru}, \mathrm{Fe} \\
& \text { (or Cat }=P t / \mathrm{Al}_{2} \mathrm{O}_{3}, \mathrm{Ru} / \mathrm{In} \text { ) }
\end{aligned}
$$

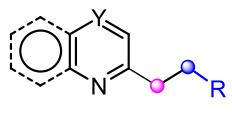

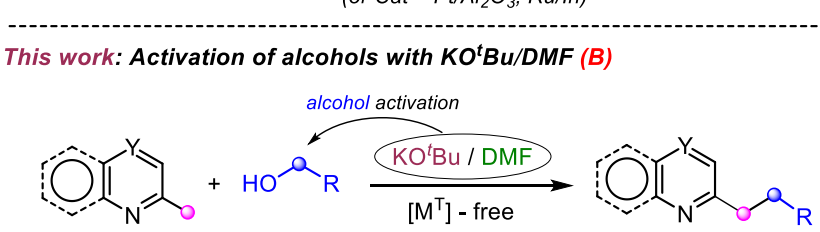

Scheme 1. Activation of alcohols and application to the $\mathrm{C}\left(\mathrm{sp}^{3}\right)-\mathrm{H}$ alkylation of methyl azaarenes.

Other systems were described with iridium, ${ }^{6}$ ruthenium, ${ }^{7]}$, ruthenium/indium, ${ }^{8}$ iron, ${ }^{9}$ platinum supported nanoclusters, ${ }^{10}$ nickel ${ }^{11}$ or cobalt based catalysts. ${ }^{12}$ In almost all of these methods, the borrowing-hydrogen process allowed the $\mathrm{C}\left(\mathrm{sp}^{3}\right)$ $\mathrm{H}$ alkylation of methyl azaarenes in the presence of $\mathrm{KO}^{\mathrm{t}} \mathrm{Bu}$ as base, in solvents such as 1,4-dioxane, toluene, xylene, mesitylene, tetrahydrofuran or diglyme (temperatures range: 110 to $170^{\circ} \mathrm{C}$ )(Scheme $1 \mathrm{~A}$ ).

We report herein that by exchanging these solvents with DMF we were able to activate alcohols avoiding the use of transition metal catalysts, and thus to perform the $\mathrm{C}\left(\mathrm{sp}^{3}\right)-\mathrm{H}$ alkylation of methyl azaarenes (Scheme $1 \mathrm{~B}$ ). The absence of transition metals is a decisive advantage as it avoids the leaching of toxic transition metal impurities, which even at very low rate must be removed from the final target in the case of drug synthesis. A mechanism, describing the activation mode of alcohols by the $\mathrm{KO}^{t} \mathrm{Bu} / \mathrm{DMF}$ couple is proposed.

\section{Results and discussion}

To start our investigations, we chose 2-methylpyridine 1a with benzylic alcohol $2 \mathrm{a}$ as the template substrates. 2-methylpyridine is a very good marker to test the efficiency of our system as it has often shown low reactivity for the alkylation with alcohols performed in the presence of transition metal based catalysts (borrowing- 
hydrogen process - Scheme 1). ${ }^{[5-12]}$ We first reacted $1 \mathrm{a}$ with $2 \mathrm{a}$ in DMF $(1 \mathrm{~mL})$ for $24 \mathrm{~h}$ at $140^{\circ} \mathrm{C}$ in the presence of 1 equivalent of $K O^{t} \mathrm{Bu}$. Due to the absence of reactivity, we increased the loading of the base up to 4 equivalents and observed the selective formation of the expected C-alkylation product 3aa in 52\% yield (Table 1 entries 1-3), traces of the corresponding stilbene derivative being sometimes detected. Using other bases such as $\mathrm{NaOH}, \mathrm{CsOH}, \mathrm{Cs}_{2} \mathrm{CO}_{3}$ or $\mathrm{K}_{3} \mathrm{PO}_{4}$ failed to furnish 3aa (Table 1, entries 4-7) and this was also observed when replacing DMF with non-polar or polar solvents, including 1,4dioxane, toluene, $\mathrm{N}$-methyl-2-pyrrolidone, chlorobenzene, $\mathrm{N}, \mathrm{N}$ dimethylacetamide, acetonitrile, 1,2-dimethoxyethane or dimethyl sulfoxide (Table 1, entry 8 ).

Table 1. $\mathrm{C}\left(\mathrm{sp}^{3}\right)-\mathrm{H}$ alkylation of 2-methylpyridine 1a with benzylic alcohol 2a, in the presence of $K O^{t} \mathrm{Bu} / \mathrm{DMF}$ : reaction conditions. ${ }^{\left[{ }^{[a]}\right.}$

\begin{tabular}{|c|c|c|c|c|c|c|c|}
\hline Entry & $\begin{array}{l}\text { Bas } \\
\text { (equi }\end{array}$ & & $\begin{array}{l}\text { Yield of } \\
\text { 3aa (\%) }{ }^{[b]}\end{array}$ & Entry & $\begin{array}{l}\text { Base } \\
\text { (equiv.) }\end{array}$ & & $\begin{array}{c}\text { Yield of } \\
\text { 3aa }(\%)^{[b]}\end{array}$ \\
\hline 1 & KOtBu & 1 & 0 & 8 & KOtBu & 4 & $0^{[c]}$ \\
\hline 2 & $\mathrm{KO} \mathrm{tBu}$ & 2 & 20 & 9 & $\mathrm{LiOtBu}$ & 4 & 0 \\
\hline 3 & $\mathrm{KO} t \mathrm{Bu}$ & 4 & 52 & 10 & $\mathrm{NaOtBu}$ & 4 & 25 \\
\hline 4 & $\mathrm{NaOH}$ & 4 & 0 & 11 & $\mathrm{KOtBu}$ & 4 & $56^{[d]}$ \\
\hline 5 & $\mathrm{CsOH}$ & 4 & 0 & 12 & KOtBu & 4 & $76^{[\mathrm{ee}]}(70)^{[\mathrm{ft}}$ \\
\hline 6 & $\mathrm{Cs}_{2} \mathrm{CO}_{3}$ & 4 & 0 & 13 & $\mathrm{KO} B \mathrm{Bu}$ & 4 & $78^{[\mathrm{d}, \mathrm{e}, \mathrm{g}]}$ \\
\hline 7 & $\mathrm{~K}_{3} \mathrm{PO}_{4}$ & 4 & 0 & 14 & $\mathrm{KOtBu}$ & 0 & 0 \\
\hline
\end{tabular}

[a] Reactions performed under argon with $0.5 \mathrm{mmol}$ of $1 \mathrm{a}$ and $1 \mathrm{mmol}$ of $2 \mathrm{a}$, in $1 \mathrm{~mL}$ of solvent. b) Yield of 3a determined by ${ }^{1} \mathrm{H}$ NMR spectroscopy as well as GC-MS with 4-iodoanisole as internal standard. [c] Solvents tested: 1,4dioxane, toluene, $\mathrm{N}$-methyl-2-pyrrolidone, chlorobenzene, $\mathrm{N}, \mathrm{N}$ dimethylacetamide, acetonitrile, 1,2-dimethoxyethane, DMSO. [d] 1a/2a ratio $=0.5 / 2$. [e] Reaction performed at $150^{\circ} \mathrm{C}$. [f] Isolated yield. [g] Reaction performed with resublimed KOtBu purchased form Alfa Aesar (99.994\%).

With other alkali alkoxides such as $\mathrm{LiO}^{t} \mathrm{Bu}$ no reactivity was observed and with $\mathrm{NaO}^{t} \mathrm{Bu}$ the $\mathrm{C}$-alkylation product 3aa was obtained in only $25 \%$ yield (table 1 , entries 9,10 ). While lowering the $\mathbf{1 a} / \mathbf{2 a}$ ratio was moderately beneficial, increasing the reaction temperature by $10^{\circ} \mathrm{C}$ afforded 3aa in $76 \%$ yield (Table 1, entries 11 , 12). We also obtained a very good yield of the $\mathrm{C}$-alkylation product using resublimed KOtBu (purchased from Alfa Aesar - 99.994\%), thus ruling out the possibility of a reaction catalyzed by undesirable metallic contaminants (table 1 , entry 13). To date this procedure is the most efficient synthetic pathway to access 3aa directly from benzyl alcohol. With the optimised conditions in hand (entry 12), we next explored the scope of the method (Table 2).

Table 2. $\mathrm{C}\left(\mathrm{sp}^{3}\right)-\mathrm{H}$ alkylation of methyl-substituted $\mathrm{N}$-hetaroarenes with alcohols: scope of the method. ${ }^{[a],[b]}$
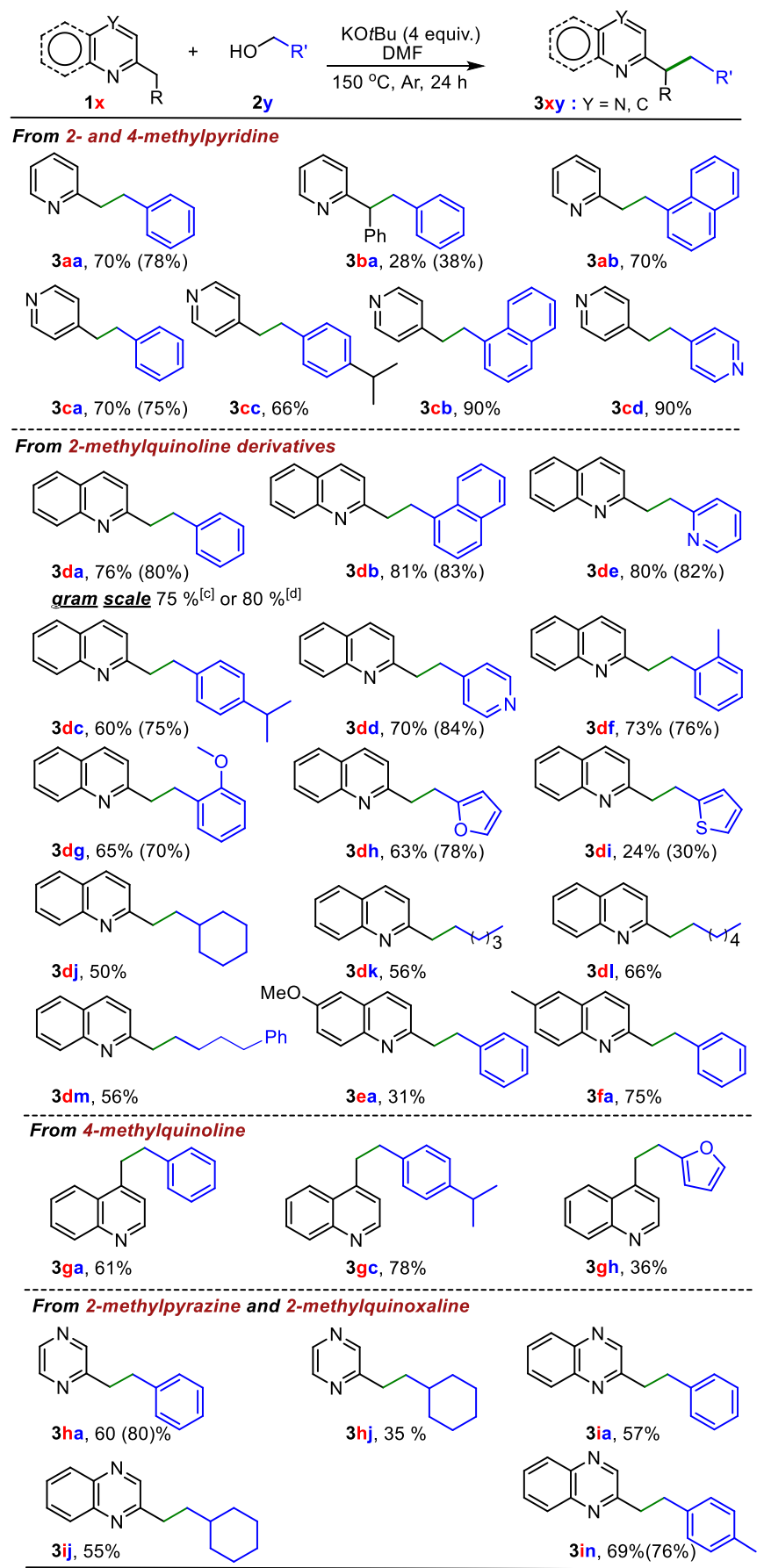

[a] Reaction conditions: $0.5 \mathrm{mmol}$ of methyl-substituted $\mathrm{N}$-hetaroarene, 2 $\mathrm{mmol}$ of benzylic alcohol, $2 \mathrm{mmol}$ of $\mathrm{KO} \mathrm{t}^{\mathrm{B}} \mathrm{B}$ in $1 \mathrm{~mL}$ of DMF, under argon. [b] Isolated yield. NMR yields, in bracket, are calculated with 4-iodoanisole as internal standard. [c] Standard conditions, $5 \mathrm{mmol}$ scale. [d] Reaction performed with $1.6 \mathrm{~mL}$ of DMF, in $14 \mathrm{~mL}$ of toluene, $5 \mathrm{mmol}$ scale.

From the benzylic alcohol $\mathbf{2 a}$ and $\mathbf{1 a}(\mathrm{pKa}=34)$ or 4 -methylpyridine $1 \mathrm{c}(\mathrm{pKa}=32.2)$, the corresponding $\mathrm{C}$-alkylation products $3 \mathrm{aa}$ and $\mathbf{3} \mathrm{ca}$ were obtained in good yield under standard conditions while from 3methylpyridine for which the methyl protons are less acidic (pKa = 37.7), only traces of the product were observed (Table 2). ${ }^{13} \mathrm{~A}$ fair yield of 3 ba was observed from 2-benzylpyridine $1 \mathbf{b}$, but good to excellent yields were obtained from $1 \mathrm{a}$ and $1 \mathrm{c}$ with other alcohols such as 1-naphthalenemethanol, 4-pyridinemethanol or (4-isopropylphenyl)methanol (Table 2, 3ab, 3cc to $\mathbf{3 c d}$ ). These results 
differ in an interesting way from transition metal catalyzed borrowing-hydrogen processes, which are usually not very efficient for the C-alkylation of 2- and 4-methylpyridine. ${ }^{5-12}$ We then studied the reaction from 2-methylquinoline $\mathbf{1 d}$ (pKa of 25 for the methyl proton), the deprotonation of which should be easier than from 2methylpyridine. ${ }^{14}$ The procedure, tested with various alcohols including 2a, 1-naphthalenemethanol, 2- or 4-pyridinemethanol, (4iso-propylphenyl)methanol, 2-methyl- or 2-methoxybenzyl alcohols, efficiently led to the expected products (3da to $3 \mathrm{dg}$ ). 2Furanemethanol, 2-thiophenemethanol, cyclohexylmethanol, pentanol, hexanol and 4-phenylbutanol also underwent alkylation of 2-methylquinoline to give the desired products ( $3 \mathrm{dh}$ to $3 \mathrm{dm}$ ), and the method was also applicable to benzylic alcohol with substituted 6methoxy-2-methylquinoline and 2,6-dimethylquinoline (3ea to $\mathbf{3 f a}$ ). 4-Methylquinoline (pKa of 25 for the methyl proton) ${ }^{14}$ also proved to be a suitable substrate for the reaction (products $\mathbf{3 g a}, \mathbf{3 g c}, \mathbf{3 g h}$ ) and from the 2-methylpyrazine or 2-methylquinoxaline, good yields of the alkylation products were obtained with benzylic, cyclohexylmethanol and 4-methylbenzylic alcohols (3ha, 3hj, 3ia, 3ij, 3in). Note that the reaction also proved to be suitable for scale-up experimentation ( $5 \mathrm{mmol}$ ), delivering the product $3 \mathrm{da}$ in an excellent yield (Table 2 ).

We then turned our attention to the reaction mechanism and chose 2-methyl quinoline $\mathbf{1 d}$ as a model for the study. We first attempted its reaction with $2 a$, in the presence of one equivalent of (2,2,6,6-tetramethylpiperidin-1-yl)oxyl (TEMPO), a common radical scavenger, and observed the formation of the alkylation product $3 \mathrm{da}$ with a good yield (86 \%) (Scheme 2; Eq. 1). ${ }^{15}$ Consequently, we assumed that the reaction did not involve a radical pathway.

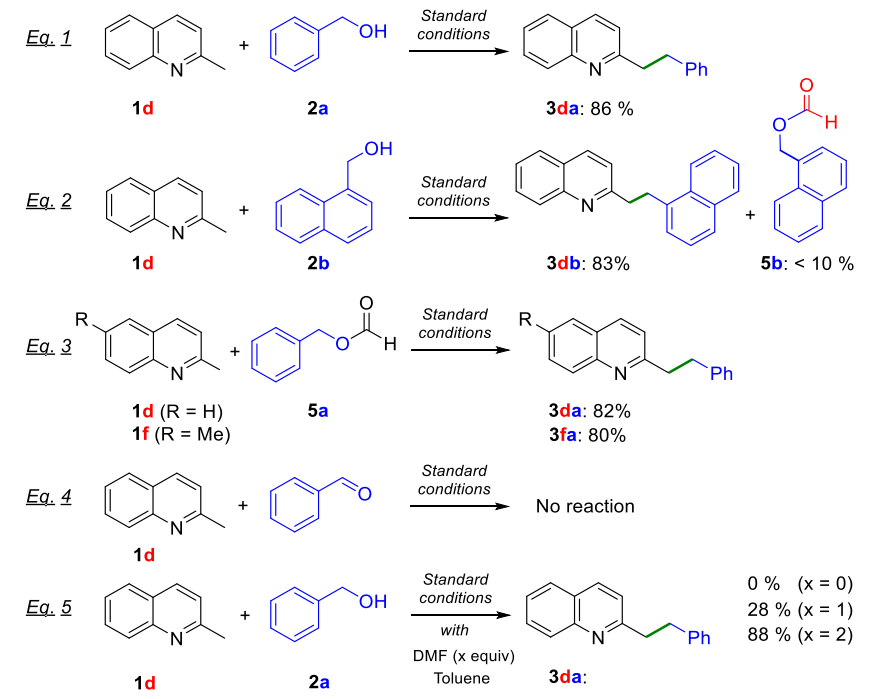

Scheme 2. Control experiments for preliminary mechanistic studies.

In our proposed mechanism, the deprotonated form of the methyl azaarene $\left(\mathbf{1}^{\prime} \mathbf{x}\right)$ reacts with an alkyl formate $5 y$, thus leading via a fourcentered intermediate to the expected alkylation product $\mathbf{3 x y}$, while releasing potassium formate. The latter probably evolves to carbon monoxide and water (Scheme 3). ${ }^{16} 5 y$ Would result from the reaction of DMF with the alcoholate 2'y, the methyl $N$-heteroarene being deprotonated by $\mathrm{KO}^{t} \mathrm{Bu}$ or the in situ generated potassium dimethyl amide. ${ }^{17}$ The formation of the alkyl formate $5 y$ was sometimes observed but in small amounts ( $<10$ mol\% for 5b), starting for example from 1-naphthalenemethanol $\mathbf{2 b}$ (Scheme 2, Eq. 2). In another control experiment, we also verified that the benzyl formate 5 a was indeed capable of reacting with 2-methyl quinoline $1 \mathrm{~d}$ or 2,6dimethylquinoline $\mathbf{1 f}$ to give, almost quantitatively, the corresponding alkylation products (Scheme 2, Eq. 3). Note that we have also envisioned a reaction route involving the intermediate formation of an aldehyde from the alcohol $2 y$ and its reaction with a methyl $\mathrm{N}$-heteroarene. However, when we tested this possibility (from $1 \mathrm{~d}$ and benzaldehyde) under standard conditions, no reaction was observed (Scheme 2, Eq. 4). In another test, using toluene as the solvent, we reacted the 2 -methylquinoline $1 \mathrm{~d}$ with the benzylic alcohol $2 \mathrm{a}$, adding various amounts of DMF. While in toluene alone, no reactivity was observed, the addition of one and two equivalents of DMF led to the formation of the expected product 3da in respectively $28 \%$ and $88 \%$ yield (Scheme $2, \underline{E q}$. 5). These results are compatible with our hypothesis suggesting that the DMF acts as a reagent in the formation of an alkyl formate $5 y$ from the corresponding alcoholate (Scheme 3).

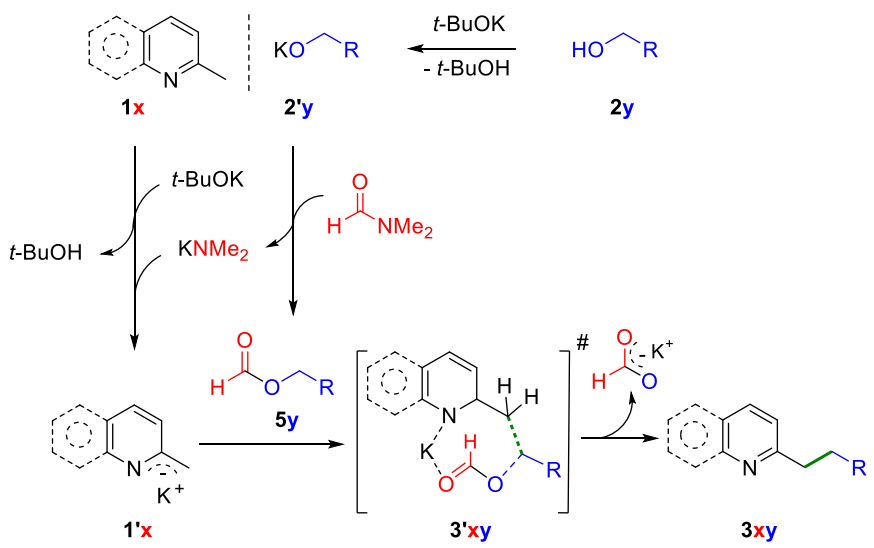

Scheme 3. Proposed mechanism for the C-alkylation of methyl pyridines and derivatives with alcohols, promoted by the KO ${ }^{t} \mathrm{Bu} / \mathrm{DMF}$ system.

In order to assess these hypotheses, a modelling study by DFT was performed at the $(M 06-2 X / 6-311+G(d, p))$ level of theory, the influence of the solvent was taken into account using the polarizable continuum model (PCM) (see Figure 1 and the Supporting Information). Based on the 2-methyl pyridine 1a and the benzylic alcohol $2 \mathrm{a}$ the simulations indicate that the reaction between the in situ generated alcoholate 2'a and DMF can lead to the formation of a "complexed" intermediate 5 'a with a quite low activation barrier $\left(E_{\mathrm{a}}=16.04 \mathrm{kcal} \mathrm{mol}^{-1}\right)$. The latter could then release the potassium dimethyl amide $\mathrm{KNMe}_{2}$ to yield the corresponding benzyl formate 5a. This reaction is not thermodynamically favourable but the benzyl formate can be engaged with the deprotonated 2-methyl pyridine 1'a in the next step, which without a doubt, represents the driving force of the overall reaction. The kinetics of this step is not easy (activation energy of $46.98 \mathrm{kcal} \mathrm{mol}^{-1}$ ) but is in accordance with the experimental data (heating and reaction time). The deprotonation of 1a can easily take place with the in situ generated $\mathrm{KNMe}_{2}\left(\mathrm{TS}=10.49 \mathrm{kcal} \mathrm{mol}^{-1}\right)$. Nevertheless, the intervention of $\mathrm{KO} \mathrm{T}^{\mathrm{B} u}$ is also possible and probably more favourable. Indeed, even if the corresponding deprotonation transition state increased (16.77 
vs $\left.10.49 \mathrm{kcal} \mathrm{mol}^{-1}\right)$, compound 1'a is found in this case to be higher in energy, which brings it closer to the TS of the final stage $(24.83$ vs $46.98 \mathrm{kcal} \mathrm{mol}^{-1}$ ), rendering the kinetics significantly more favourable.

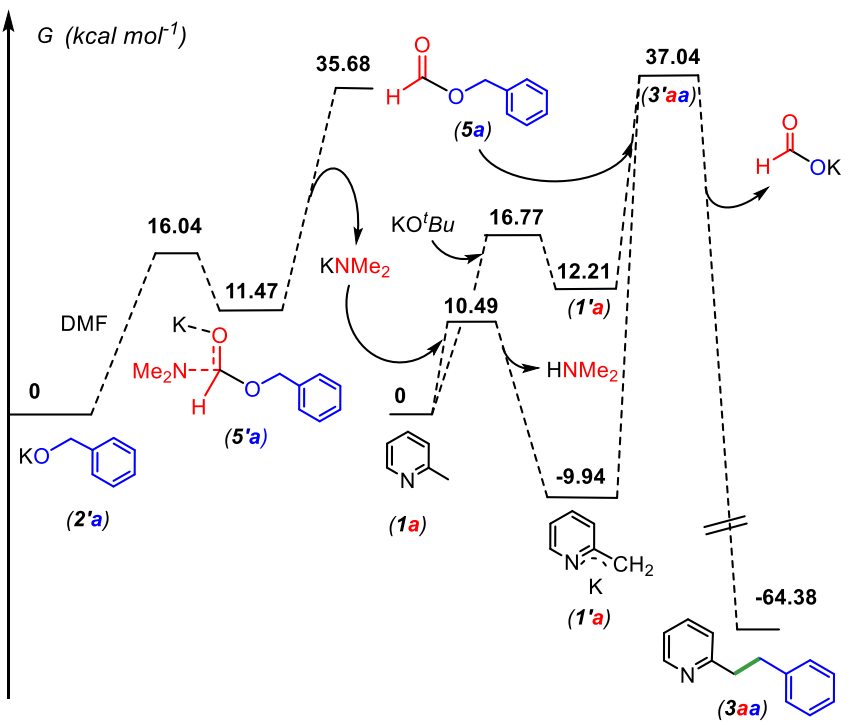

Figure 1. Gibbs energies levels $(G)$ for all steps of the reaction starting from the alcoholate. M06-2X/6-311++G(d,p) level of theory, in DMF, is used. G values are given in $\mathrm{Kcal}^{\mathrm{mol}}{ }^{-1}$. Modelling based on 2-methyl pyridine 1a and the benzylic alcohol $\mathbf{2 a}$ (represented) and on 2-methyl quinoline $\mathbf{1 d}$ with $\mathbf{2 a}$ (see $\mathrm{SI}$ ).

A modelling approach was also performed from the 2-methyl quinoline 1d (see supporting information). If the deprotonation step seems to be slightly more favourable than for 1a (9.25 vs $10.49 \mathrm{kcal}$ $\mathrm{mol}^{-1}$ ) the addition of the benzyl formate 5 a remains as difficult as in the case of 1'a (activation energy of $49.47 \mathrm{kcal} \mathrm{mol}^{-1}$ ) justifying the use of an adapted temperature and reaction time. From this comparison, one can expect quite similar behavior for $1 \mathrm{a}$ and $\mathbf{1} \mathbf{d}$. This is in accordance with the results (Table 2 ) and it is a feature of our system compared to the transition metal catalyzed borrowinghydrogen process, for which the C-alkylation of 2- and 4-methyl pyridine is generally much less effective than with other methyl $\mathrm{N}$ heteroarenes, such as 2-methyl quinoline.

\section{Conclusions}

In summary, we have disclosed a very simple new way to make alcohols more reactive, thus avoiding drawbacks linked to their activation by protonation or prefunctionalization. This was possible with potassium tert-butoxide (KO$\left.{ }^{t} \mathrm{Bu}\right)$ associated with dimethylformamide (DMF), which allowed alcohols to act as alkylating reagents with methyl azaarenes. Various pyridine, quinoline, pyrazine or quinoxaline derivatives, which are key molecules in pharmaceuticals, agrochemicals or in materials, have thus been synthesized. Compared to the borrowing hydrogen process, the modern way to perform this transformation, our system is very simple as it avoids the use of transition metal based catalysts. As our method allows the C-alkylation of methyl pyridines, it also differs in an interesting way from the borrowing-hydrogen route which is not very efficient with such substrates. The same base (KOtBu) is used in both the borrowing-hydrogen processes and in our system, allowing DMF to formally replace the transition metal catalyst. Its crucial role was rationalized by experimental and computational studies and a mechanism involving the activation of the alcohol as an alkyl formate intermediate is proposed.

From a general point of view, this new procedure represents a welcome alternative in the field of alcohol activation and efforts to expand its utility for example towards olefination reactions, alongside mechanistic studies, are in progress and will be reported in due course.

\section{Author Contributions}

X. L. conducted all of the synthetic experiments. J.-M. S. performed DFT calculations and M.T. wrote the paper. All authors provided feedback and contributed to editing the manuscript.

\section{Conflicts of interest}

There are no conflicts to declare.

\section{Acknowledgements}

We thank the Institut de France, Académie des Sciences for Financial support, the China Scholarship Council (CSC) for a grant to Mr. Xiaoping LIU, the Centre National de la Recherche Scientifique (CNRS), the Ecole Nationale Supérieure de Chimie de Montpellier (ENSCM), and the "Direction du Numérique" of the Université de Pau et des Pays de l'Adour. MCIA (Mésocentre de Calcul Intensif Aquitain) and CINES under allocation A005080045 made by Grand Equipement National de Calcul Intensif (GENCI) are acknowledged for computational facilities.

\section{Notes and references}

1 a) Z. Sun, G. Bottari, A. Afanasenko, M. C. A. Stuart, P. J. Deuss, B. Fridrich and K. Barta, Complete lignocellulose conversion with integrated catalyst recycling yielding valuable aromatics and fuels, Nat. Catal. 2018, 1, 82-92. b) T. Irrgang and R. Kempe, 3d-Metal Catalyzed N- and C-Alkylation Reactions via Borrowing Hydrogen or Hydrogen Autotransfer, Chem. Rev. 2019, 119, 2524-2549.

2 a) A. J. A. Watson and J. M. J. Williams, The give and take of alcohol activation, Science 2010, 329, 635-636. b) F. Alonso, F. Foubelo, J. C. González-Gómez, R. Martínez, D. J. Ramón, P. Riente and M. Yus, Efficiency in chemistry: from hydrogen autotransfer to multicomponent catalysis, Mol. Diversity 2010, 14, 411-424. c) F. Huang, Z. Liu and Z. Yu, C-Alkylation of Ketones and Related Compounds by Alcohols: TransitionMetal-Catalyzed Dehydrogenation, Angew. Chem. 2016, 128, 872-885; Angew. Chem. Int. Ed. 2016, 55, 862-875.

3 a) J. A. Joule and K. Mills, Heterocyclic Chemistry, Blackwell, Oxford, UK, 4th edn, 2000; b) J. P. Michael, Quinoline, quinazoline and acridone alkaloids, Nat. Prod. Rep. 2007, 24, 223-246; c) B. M. Trost and D. A. Thaisrivongs, Strategy for Employing Unstabilized Nucleophiles in Palladium-Catalyzed Asymmetric Allylic Alkylations, J. Am. Chem. Soc., 2008, 130, 14092-14093. d) A. Pozharskii, A. Soldatenkov and A. Katritzky, In Heterocycles in Life and Society: An Introduction to Heterocyclic Chemistry, Biochemistry and Applications; John Wiley \& Sons, 2011; e) D. Srimani, Y. Ben-David and D. Milstein, Direct synthesis of pyridines and quinolines by coupling of $y$-amino-alcohols with secondary alcohols liberating $\mathrm{H}_{2}$ catalyzed by ruthenium pincer complexes, Chem. 
Commun. 2013, 49, 6632-6634; f) E. Vitaku, D. T. Smith and J. T. Njardarson, Analysis of the Structural Diversity, Substitution Patterns, and Frequency of Nitrogen Heterocycles among U.S. FDA Approved Pharmaceuticals, J. Med. Chem. 2014, 57, 10257-10274; g) J. Jin and D. W. C. MacMillan, Alcohols as alkylating agents in heteroarene $\mathrm{C}-\mathrm{H}$ functionalization, Nature, 2015, 525, 87-90; h) A. P. Taylor, R. P. Robinson, Y. M. Fobian, D. C. Blakemore, L. H. Jones and O. Fadeyi, Modern advances in heterocyclic chemistry in drug discovery, Org. Biomol. Chem. 2016, 14, 6611-6637; i) M. Stępień, E. Gońka, M. Żyła and N. Sprutta, Heterocyclic Nanographenes and Other Polycyclic Heteroaromatic Compounds: Synthetic Routes, Properties, and Applications, Chem. Rev. 2017, 117, 3479-3716; j) P. Xu, P.-Y. Chen and H.C. Xu, Scalable Photoelectrochemical Dehydrogenative CrossCoupling of Heteroarenes with Aliphatic C-H Bonds, Angew. Chem. 2020, 132, 14381-14386; Angew. Chem. Int. Ed. 2020, 59, 14275-14280.

4 a) R. V. Stevens and J. W. Canary, Synthesis of 2-Octalones from Quinaldine, J. Org. Chem. 1990, 55, 2237-2240; b) E. Pasquinet, P. Rocca, F. Marsais, A. Godard and G. Queguiner, On the metallation of 2-isopropylpyridine, Tetrahedron 1998, 54, 8771-8782; c) V. Martinez, C. Burgos, J. Alvarez-Builla, G. Fernandez, A. Domingo, R. Garcia-Nieto, F. Gago, I. Manzanares, C. Cuevas and J. J. Vaquero, Benzo[f]azino[2,1a]phthalazinium Cations: Novel DNA Intercalating Chromophores with Antiproliferative Activity, J. Med. Chem. 2004, 47, 1136-1148; d) B. M. Trost, D. A. Thaisrivongs, Strategy for Employing Unstabilized Nucleophiles in Palladium-Catalyzed Asymmetric Allylic Alkylations, J. Am. Chem. Soc., 2008, 130, 14092-14093; e) B. M. Trost and D. A. Thaisrivongs, Palladium-Catalyzed Regio-, Diastereo-, and Enantioselective Benzylic Allylation of 2-Substituted Pyridines, J. Am. Chem. Soc., 2009, 131, 12056-12057; f) B. M. Trost, D. A. Thaisrivongs and J. Hartwig, Palladium-Catalyzed Asymmetric Allylic Alkylations of Polynitrogen-Containing Aromatic Heterocycles, J. Am. Chem. Soc., 2011, 133, 1243912441 ; g) M. Xiao, D. Ren, L. Xu, S. S. Li, L. Yu and J. Xiao, $\mathrm{S}_{\mathrm{N}} 1$ Type Alkylation of $\mathrm{N}$-Heteroaromatics with Alcohols, Org. Lett., 2017, 19, 5724-5727; h) R. Niu, J. Xiao, T. Liang, X. Li, Facile Synthesis of Azaarene-Substituted 3-Hydroxy-2oxindoles via Brønsted Acid Catalyzed sp3 $\mathrm{C}-\mathrm{H}$ Functionalization, Org. Lett. 2012, 14, 3, 676-679; i) L. Xu, Z. Shao, L. Wang, J. Xiao, Tandem $\mathrm{sp}^{3} \mathrm{C}-\mathrm{H}$ Functionlization/Decarboxylation of 2-Alkylazaarenes with Coumarin-3-carboxylic Acids, Org. Lett. 2014, 16, 796-799; j) S. Li, S. Fu, L. Wang, L. Xu, J. Xiao, $t$-BuOK-Mediated Oxidative Dehydrogenative $\mathrm{C}\left(\mathrm{sp}^{3}\right)-\mathrm{H}$ Arylation of 2-Alkylazaarenes with Nitroarenes, J. Org. Chem. 2017, 82, 8703-8709.

5 B. Blank and R. Kempe, Catalytic Alkylation of Methyl- $N$ Heteroaromatics with Alcohols, J. Am. Chem. Soc. 2010, 132, 924-925.

6 a) Y. Obora, S. Ogawa and N. Yamamoto, Iridium-Catalyzed Alkylation of Methylquinolines with Alcohols, J. Org. Chem. 2012, 77, 9429-9433; b) Z. Tan, H. Jiang, M. Zhang, A novel iridium/acid co-catalyzed transfer hydrogenative $\mathrm{C}\left(\mathrm{sp}^{3}\right)-\mathrm{H}$ bond alkylation to access functionalized $N$-heteroaromatics, Chem Commun. 2016, 52, 9359-9362; c) M. Onoda and K.-I. Fujita, Iridium-Catalyzed C-Alkylation of Methyl Group on NHeteroaromatic Compounds using Alcohols, Org. Lett. 2020, 22, 7295-7299.

7 T.-Y. Feng, H.-X. Li, D. J. Young and J.-P. Lang, Ligand-Free $\mathrm{RuCl}_{3}$-Catalyzed Alkylation of Methylazaarenes with Alcohols, J. Org. Chem. 2017, 82, 4113-4120.

8 Y. Nakamura, A. Azuma, S. Kato, Y. Oe and T. Ohta, Alkylation of the Methyl Group of 2-Methylquinolines and Similar Methyl- $N$-Heteroaromatics with a Ru/In Dual Catalyst, Chemistry Letters 2019, 48, 1192-1195.
9 L. M. Kabadwal, S. Bera and D. Banerjee, Iron-catalysed alkylation of 2-methyl and 4-methyl azaarenes with alcohols via $\mathrm{C}-\mathrm{H}$ bond activation, Chem Commun. 2020, 56, 47774778.

10 Chaudhari, S. M. A. Hakim Siddiki and K.-I. Shimizu, Alkylation of 2-methylquinoline with alcohols under additive-free conditions by $\mathrm{Al}_{2} \mathrm{O}_{3}$-supported Pt catalyst, Tetrahedron Lett. 2013, 54, 6490-6493.

11 a) J. Rana, R. Babu, M. Subaramanian and E. Balaraman, NiCatalyzed dehydrogenative coupling of primary and secondary alcohols with methyl- $N$-heteroaromatics, Org. Chem. Front. 2018, 5, 3250-3255; b) M. Vellakkaran, J. Das, S. Bera and D. Banerjee, Nickel-catalysed alkylation of $\mathrm{C}\left(\mathrm{sp}^{3}\right)-\mathrm{H}$ bonds with alcohols: direct access to functionalised $\mathrm{N}$ heteroaromatics, Chem Commun. 2018, 54, 12369-12372.

12 A. Mishra, A. D. Dwivedi, S. Shee and S. Kundu, Cobaltcatalyzed alkylation of methyl-substituted $\mathrm{N}$-heteroarenes with primary alcohols: direct access to functionalized $\mathrm{N}$ heteroaromatics, Chem Commun. 2020, 56, 249-252.

13 For the pKa of pyridine derivatives see: a) J. A. Joule and K. Mills, Heterocyclic Chemistry, John Wiley\& Sons Ltd., West Sussex, U.K., 2013, pp. 54-55. Heterocyclic Chemistry, 5th Edition; b) M. J. P. Mandigma, M. Domański and J. P. Barham, C-Alkylation of alkali metal carbanions with olefins, Org. Biomol. Chem., 2020, 18, 7697-7723.

14 a) T. J. Batterham, D. J. Brown and M. N. Paddon-Row, Simple pyrimidines. Part IX. Deuterium exchange of C-methyl protons, J. Chem. Soc. B 1967, 171-173; b) A. Fischer, M. W. Morgan and C. Eaborn, Rates of base-catalysed cleavage of pyridyl-, quinolyl-, picolyl- and (quinolylmethyl)trimethylsilanes, J. Organomet. Chem. 1977, 136, 323-332.

15 For examples of radical mechanism based on the use of the couple KO ${ }^{t} B u / D M F$ see: a) M. P. Drapeau, I. Fabre, L. Grimaud, I. Ciofini, T. Ollevier and M. Taillefer, Transition-Metal-Free $\alpha$ Arylation of Enolizable Aryl Ketones and Mechanistic Evidence for a Radical Process, Angew. Chem. 2015, 127, 10733-10737; Angew. Chem. Int. Ed. 2015, 54, 10587-10591. b) M. Pichette Drapeau, T. Ollevier and M. Taillefer, FR, 2014-0057458, WO 2016-016414. c) J. P. Barham, G. Coulthard, K. J. Emery, E. Doni, F. Cumine, G. Nocera, M. P. John, L. E. A. Berlouis, T. M. McGuire, T. Tuttle and J. A. Murphy, KOtBu: A Privileged Reagent for Electron Transfer Reactions?, J. Am. Chem. Soc. 2016, 138, 7402-7410.

16 A. Imberdis, G. Lefèvre and T. Cantat, Transition-Metal-Free Acceptorless Decarbonylation of Formic Acid Enabled by a Liquid Chemical-Looping Strategy, Angew. Chem. 2019, 131, 17375-17379; Angew. Chem. Int. Ed. 2019, 58, 17215-17219.

$17 \mathrm{~K}$. Azizi and R. Madsen, Radical condensation between benzylic alcohols and acetamides to form 3arylpropanamides, Chem. Sci., 2020, 11, 7800-7806. 